\title{
Is there a need for change in scientific communication and can open access take on this role?
}

\author{
Aleksandar Dimchev* and Rosen Stefanov \\ Sofia University "St. Kliment Ohridski”, Sofia, Bulgaria
}

\begin{abstract}
The paper presents a brief historical analysis and outline of the contemporary issues of the 'open access' initiative. The beginning of the 'OA' movement to scientific publications emerged in the 1990s of the 20th century and was associated with the possibilities of providing free and quick access for scientists to scientific information online, as well as the idea of overcoming financial barriers. The paper provides an overview of current tendencies and models of application in regards to this publication model. The evaluations presented in this paper are carried on the basis of analyses and studies of the evolution of open access in the past decade. On this ground the conclusion is drawn, that in spite of the difficulties, barriers and resistance, the achievements made so far show some optimism for the future of OA. The first steps in this regard are taken through the creation of a more effective and cheaper global network for communication in science, which possesses and distributes enormous databases. Such a system should outline the road to coordination and relationship within particular fields of knowledge. It should also resolve a basic question, namely the possibility of the representatives of research communities at large, regardless where they are, to work in an interactive mode throughout the entire research cycle - from the exchange of ideas, research methods, instruments, data, and information to the final result of their collective labor. Additionally, this report also provides a short examination of OA within the context of both international practices (with a focus on European experience in the Open Access field, as well as looking at the current tendencies regarding this publishing model in Bulgaria).
\end{abstract}

Keywords: Open access, OA movement, "green" and "golden" roads, transformation of communication channels in science, global perspectives, tendencies in Bulgaria

\section{A brief introduction to open access}

We shall begin this paper with the inspiring words of one of the most ardent supporters of "open access (OA)", which is increasingly becoming a major phenomenon in academic circles. The first quote is that of Lee Van Orsdel and Kathleen Born, from their publication, which was met with due interest and debates "Periodicals Price Survey 2008. Embracing Openness. Global initiatives and startling successes hint at the profound implications of open access on journal publishing" [24]. "They have argued about it for years. It's been touted as the liberator of information that wants to be free, the arbiter of shared intellectual property rights, and an engine that can drive discovery, invention, cures, and economies. It has also been vilified as an assault on capitalism, a catalyst for the collapse of responsible publishing and the rise of junk science, and a naïve invention of some pointy-headed idealists who have no idea how the real world works". "It", of course, is open access (OA). Evidence for open access as an emergent, global state of mind can be found everywhere. Increasingly, scholarly communities are breaking with

\footnotetext{
*Corresponding author. E-mail: dimchev_uni@abv.bg.
} 
tradition and calling for the open sharing of research, software, and data. Amongst these global initiatives is the campaign to provide open access to the results of research that is funded with public funds. That campaign has produced a series of startling successes in recent months, with potentially profound implications for the journal publishing industry".

The beginnings of the 'OA movement' for academic publications emerged in the 1990s of the past century. It was associated with the possibility of the provision of free and quick access of scientific information in an online mode of access together with the idea of overcoming financial barriers associated with "traditional" publishing models [14]. In 1991, the Los Alamos-based physicist Paul Ginsparg proposed the creation of an open access electronic archive for materials published by his colleagues and other experts working in the field of nuclear physics and its related scientific fields [15]. Three years later, another scientist - Stevan Harnad published his famous subversive proposals, where he suggests self-archiving in the Web through the publishing of ones work in a site. The author notes that openness of research results would "contribute to a maximum degree for new ideas reaching the eyes and minds of participants in the Web, scientists from all over the world, and dealing with research problems" [10]. These proposals caused an active discussion amidst representatives of various research communities. Among these research communities were also specialists from the library and information sectors. The Association of Research Libraries in U.S.A. published materials on the polemics in 1995. We should emphasize that over the years librarians have played a substantial part for the development of OA [21,22]. Thus, to a certain degree, the paths of both scientists, as well as library specialists merge in a common movement for open access, where key minds such as Stevan Harnad (among others) play an integral role in defining the role of open access to information [15]. According to Stevan Harnad "the specific OA content is that of 2.5 million academic papers published every year in 25,000 peer-reviewed journals in the world, in particular in the field of science and natural science" [10]. OA also includes research materials which authors would be willing to share with the greater scientific community: software, audio and video material. Nevertheless, it would be correct to emphasize that the majority of OA are articles from peer-reviewed scientific journals. "The authors of these articles are interested in their studies gaining fame, and being cited, as well as becoming the basis of future research projects and developments in their respective fields. Active quoting, and resorting to journals is known to form 'academic contributions" of authors" [15] (see "Notes").

\section{Open access: Definitions}

There are a great number of definitions and interpretations of open access. The interpretations of what open access can be are, to large extent, tied to the continuous development of technology and its application. The discussions regarding open access and its definition have birthed several major topic specific forums and events. Of key importance among these are the forums that were held at Budapest (2001), Bethesda (2003) and Berlin (2003). According to Charles Bailey, a specialist in communications, among the most accurate definitions of OA are those adopted at the Budapest Open Access Initiative: "The literature that should be freely accessible is that which scholars give to the world without expectation of payment" [2]. Primarily, this encompasses their peer-reviewed journal articles, but also includes any reviewed preprints that they might wish to put online for comment or to alert colleagues to important research findings. There are many degrees and kinds of wider and easier access to this literature. By "open access" to this literature we mean its free availability on the public domains of the World Wide Web, permitting any users to read, download, copy, distribute, print, search or link the full text of these materials, crawl them for indexing, pass them as data to software or use them for any other lawful purpose (a 
very important point to note: OA does not translate to the abolishment of copyright), without financial, legal of technical barriers other than those inseparable from gaining access to the Web itself. The only constraint on reproduction and distribution, and the only role for copyright in this domain, should be to give authors control over the integrity of their work and the right to be properly acknowledged and cited. At the Bethesda forum held in 2003, the definition was enriched in the following meaning "The author(s) and copyright holder(s) grant(s) to all users a free, irrevocable, worldwide, perpetual right of access to, and a license to copy, use, distribute, transmit and display the work publicly and to make and distribute derivative works, in any digital medium for any responsible purpose, subject to proper attribution of authorship, as well as the right to make small numbers of printed copies for their personal use. A complete version of the work and all supplemental materials, including a copy of the permission as stated above, in a suitable standard electronic format is deposited immediately upon initial publication in at least one online repository that is supported by an academic institution, scholarly society, government agency, or other well-established organization that seeks to enable open access, unrestricted distribution, interoperability, and long-term archiving (for the biomedical sciences, PubMed Central is such a repository)" [2]. Peter Suber, one of the most ardent believers and supporters of the ideas for open access offers the following definition: "open access removes "price barriers" ("e.g., subscription fees") and "permission barriers" ("e.g., copyright and licensing restrictions") to "royalty-free literature" ("i.e., scholarly works created for free by authors"), making them available with "minimal use restrictions" ("e.g., author attribution")" [15]. Later he raises the issue of summarizing the Budapest Open Access Initiative, Bethesda Statement, and Berlin Declaration definitions. He has called his upgraded version "BBB definition of open access" and he notes that this definition removes both price and permission barriers. However, Suber asserts elsewhere that "Removing price barriers alone will give most OA proponents most of what they want and need" [15]. Harnad continues his thesis with the following stand "an even more optimal solution for the placing of the electronic version of a document in the regime of open access in the internet. Namely this technology is the basis of what we call "open access": free of charge, operative, regular access in reviewed scientific journals" [10]. Charles Bailey has introduced a substantial fact connected with the right for the functioning of open access. "It should be noted that open access is rooted in existing copyright law: copyright owners permit users to freely access their works and grant them additional rights that remove permission barriers. Open access does not require that copyright laws change in order for it to exist" [2].

\section{Factors for the development of open access}

In the last couple of years there have been several key changes in the fields of information dissemination and publication that have, to a large extent, enabled the rise of open access as a viable publication model. These include:

- the rapid onset of changes and advancement in the field of information and communication technologies;

- the exponential increase of the volume of data, information and publications in the field of research;

- the steady growth of prices of research information and publications (according to information from the Association of Research Libraries, the prices of journals have increased by $215 \%$ over the last fifteen years, which is a serious burden on the budget of libraries) [14];

- the rapid development of science that, in turn, necessitates the acceleration of the process of getting results and achievements in scientific research (with traditional models of publishing, there is a 
notable delay in the process bringing out academic literature: from the handing in of an initial manuscript to its publication and dissemination as a finalized publication);

- the dynamic changes that have, and continue to happen, in the publishing sector;

- the transition towards mass digitalization of scientific literature (above $95 \%$ of leading academic journals come out in electronic versions, about $35 \%$ academic monographs come out in electronic form etc.);

- the transformation in the methods of the creation, storage and presentation, distribution and information resources and products;

- the emergence of new information channels and possibilities and the way that these enable the creation and use of new means for information dissemination and storage in the scientific community;

- the search for possibilities to overcome "information isolation and uneven conditions in science";

- the refusal of society of having to pay "twice" for the research results and publications with public funds (on one hand, paying for the research process and on the other hand, paying for access to the results of said access in the form of articles, reports, databases and so on) [14].

\section{Open access and its role in the publishing world: Supporters and opponents}

Some specialists share a common view that open access represents a veritable "revolution" in regards to the dissemination and use of scientific information. They are aware of the high price and unproductiveness of the traditional means of access to scientific knowledge. They also consider the current tendencies in the field of research publication as a catalyst for a change that will lead to the emergence of better and more effective means of sharing and using information. The expectations are that these changes are going to be fundamental and decisive in nature and are going to affect the whole chain of scientific knowledge. Richard Poynder, a British journalist and historian claims that in about a decade, OA could very well become a serious threat to the traditional publishing channels.

Of course, there are also those who critique the OA model and do not consider it to be the "be all, end all" solution to the publishing woes the modern world. The latter claim that it is difficult to break the old publishing models that are based on century old practices of organization and dissemination of knowledge amongst the academic communities. They do not believe that the monopoly on information dissemination can disappear so easily and that commercial publishers and distributors will simply cease to exist with the advent of OA. In their view, these traditional players on the information market have enormous experience and control key positions and mechanisms in the creation, distribution and presentation and evaluation of scientific information and knowledge. Pessimism also comes from the position of scientists themselves, concerning the introduction of OA. Harnad very well expresses their hesitation through his metaphor "Zeno's Paralysis" [10]. The author points to the impossibility of an OA "night of wonders", which would impose itself on the arena of scientific communications. According to Harnad it has failed to set in, neither in 1994, nor in the recent years, neither to this day. Why is it so? There are multiple reasons for that. They are all psychological and for that reason, there is no ground for "threats". It is not by chance that the syndrome is acknowledged with the cited term. I fear that self-archiving of my paper shall deprive me of my copyright... or my paper shall not be peer reviewed... or shall lead to the disappearance of academic journals... or that online information means are not reliable... or that I shall not have sufficient time for self-archiving... and the list goes on. 


\section{The golden and green roads of open access}

Over the years, the initiative for open access has passed through a number of complicated questions and metaphors, in its quest for finding a place for this new publishing model. Gradually it is catching up speed and is winning supporters. Through the years, two key models of OA have emerged as alternative means for the dissemination and use of scientific information. These are commonly known as the "golden road" and "green road" models. They are defined as follows:

- the golden road - through the creation of new open access journals or the transformation of existing "traditional" journals or publications;

- the green road - achieved through the self-archiving of papers by scientist themselves or through institutional repositories related to the organizations in which these researchers work.

\section{Which of the two roads has a better future?}

In the beginning according to Alma Swan "it was easier to imagine the so called 'golden road' towards open access" [23]. The green road appeared hopelessly blocked by the limitations of copyright and the spread information in the Web.

However, despite these expectations, two key circumstances enabled the "green road" to win more support and to be accepted as the one with greater prospects (or a greater threat to publishers). The first step was the emergence of the standard for exchange of metadata. (Open Archives Initiative - Protocol for Metadata Harvesting $(O A I-P M H)$ which allows for the systematic harvesting of the contents of online repositories. The next step is the acceptance (with some reserves) of self-archiving by publishers. The conditions for permitting the carrying out of self-archiving with various publishers vary (which is considered healthy from a competitive point of view). In spite of this, the emergence of so called "green" publishers allowed a number of universities and research centers to develop institutional repositories, most often under the guidance of librarians and information specialists.

Other leading specialists share the view that the "golden road" has greater chances of having a future $[7,8]$. A number of positive developments, steps and favorable decisions give ground for such optimism. On the grounds of performed analysis, they see the "golden road" as a platform towards which all peerreviewed journals will gradually head. The Directory of Open Access Journals - DOAJ supported by the Lund University gives some practical grounds for support of this hypothesis [9,16,18]. As of 25 October 2015 DOAJ offers access to online information from up to 10,648 journals $(6,536$ searchable at article level) registered for the 2002-2015 period (from 135 countries), with 2,104,247 articles [2,18,19]. The increase in the number of OA journals for the above period is covered in Table 1.

As we are on the topic of OA journals, it might be prudent to also note of the current state of open access journals in Bulgaria as of 2015, Bulgaria ranks as 37th (from a total of 135 countries covered) in the world based on information from DOAJ (Directory of Open Access Journals) relevant as of 2015 [7]. Table 2 provides a general idea of how the number of OA journals in Bulgaria rank in comparison

Table 1

Increase of the number of journals throughout the years (information relevant as of 25.10.2015) [18,19]

\begin{tabular}{lccccc}
\hline Years & $2002-2005$ & $2006-2008$ & $2009-2010$ & $2011-2012$ & $2013-2015$ \\
\hline Total number of titles & 1,141 & 3,588 & 4,348 & 7,489 & 10,648 \\
\hline
\end{tabular}


Table 2

Bulgarian ranking in DOAJ with regards to the OA journals available to the public [10]

\begin{tabular}{clc}
\hline Rankings & \multicolumn{1}{c}{ Country } & Number of OA journals \\
\hline 1. & USA & 1,237 \\
2. & Brazil & 952 \\
3. & Great Britain & 664 \\
6. & Germany & 341 \\
9. & Romania & 307 \\
11. & Turkey & 210 \\
13. & France & 175 \\
24. & Croatia & 93 \\
25. & Serbia & 88 \\
30. & Czech Republic & 71 \\
32. & Russia & 70 \\
$\mathbf{3 7 .}$ & Bulgaria & $\mathbf{4 5}$ \\
39. & Slovenia & 41 \\
40. & Greece & 39 \\
\hline
\end{tabular}

with other countries in the world. This includes both leading countries, as well as those that are more comparable to Bulgaria in terms numbers of published open access journals.

The information provided in Table 2 indicates that the total number of OA journals in Bulgaria is fairly small in comparison with what is found in other countries in the world. Even so, these numbers are comparable with those found in other neighboring countries such as Greece and Slovenia.

\section{The impact of open access on scholarly communities and communication}

The sharp increase of OA journals throughout the world, especially during the last two years is evident, which points to a serious change in orientation of scientific journals towards the "golden road". The establishment of BioMed Central and PLoS Public Library of Sciences [3,20] in 1999 and 2001 played a substantial part in this development. The approach adopted by BioMed Central, followed by other publishers and distributors of scientific journals, is particularly instructive. BioMed Central is a publisher, which has specialized in the field of science, technologies and medicine. It has published 220 peer-reviewed medical and biological journals completely free of charge. Scientists who have published their research here retain the copyright for their papers via the Creative Commons Attribution License. In this way, papers can be used and/or re-used with no restrictions for the users, provided they are correctly cited. Financial policies in connection with the publication are an important step in this respect. BioMed Central takes on the fees for the inclusion of papers in its journals, according to certain rules, which has a stimulating effect and removes financial barriers before researchers. BioMed Central belongs to Springer Science + Science Business Media and supports the Springer Open platform. The road taken on by publishers like BioMed Central and similar ones, which have adopted its logic and position has proven successful and provides stability. The result of Roger Clarke's studies on operative costs in the models of publication of journals with peer-reviewed papers confirms the hypothesis that the costs of preparation of an electronic OA journal are lower than the costs of a journal accessible through subscription [24]. Another interesting point is the data cited by David Lewis on the future of the "golden road" $[12,13]$. The author puts forth the thesis that OA is effectively a destructive innovation. Preliminary estimates concerning the "golden road" show that 50\% of all research journals between 2017 and 2021 
shall be available through OA and towards 2025 about 90 percent shall become accessible in this mode of access. This means that the coming decade could very well see a drastic change in the way in which academic papers are published and shared amongst the scientific and research communities. A notable side-effect of these changes would be that academic libraries would no longer consider the growling cost of scientific and research journals to be such a significant issue as it is now.

Among the catalysts that led to a wider and more active spread of OA is the circumstance that it had an impact in increasing the popularity and rating of the research organizations themselves. An example of this can be found in the Southampton University, Great Britain. At first, the call for publishing of academic papers through open access was met with little active enthusiasm from the university's staff. This did not, however, signal an abrupt end for OA within Southampton. As a practical step in applying OA, the Faculties in Electronics and Computer Sciences at the university adopted a policy that promoted the self-archiving of materials published by both faculty staff, as well as students. The outcome of this was impressive, even surprising. According to indices that regard the international rating of universities (based around the "visibility" of that particular university in the Web), Southampton came in third in regards to prestige in the UK and 25th in the world. Its ranking was comparable to world renowned universities such as Columbia and Yale [10].

A clear tendency has emerged over the years: that with the publication of papers in OA there is a rapid increase of their search and use, as well as the frequency of their citation. The last point, in particular, is of great importance since an increase in citation can be equated to an increase of "visibility" for a given researcher, organization or even the greater scientific fields themselves. Table 3 presents an overview of the increase in citation per individual scientific fields.

In spite the existence of a considerable number of journals in OA and its positive effect on the intensity of citation (as seen above), many representatives from the academic community have not in fact made real steps in publishing their works through open access channels. Alma Swan has presented us with the outcome of her study in this particular topic. According to this research, in spite of scientists' positive attitude to OA, they had not published or self-archived their documents for free use. They were expected to do so when their respective university or organization had a policy of demanding their research staff deposit their materials with OA repositories. In a survey, 95 percent of researchers showed that they would offer their research papers to be published in OA, and 80 percent had answered that they had the desire to do this when universities or funding institutions propose rules and regulations for publication

Table 3

Increase of citation according to scientific fields $[9,10]$

\begin{tabular}{lc}
\hline Scientific fields & Percentage of increase of citation (\%) \\
\hline Physics & 245 \\
Sociology & 170 \\
Psychology & 110 \\
Law & 110 \\
Management & 90 \\
Education & 75 \\
Business & 75 \\
Health sciences & 60 \\
Political science & 65 \\
Economics & 45 \\
Biology & 40 \\
\hline
\end{tabular}


activities [10]. This shows that OA, while by now accepted as a means of publication, still has an aura of uncertainty surrounding it in the eyes of parts the scientific community.

\section{OA policies and initiatives: The European experience}

The proper application of open access initiatives and projects can be largely connected with the application of OA specific policies. These include both institutional and organizational policies, as well as those put into action by government agencies. One of, arguably, the most important of these was the "DRIVER" initiative (as of 2009, the DRIVER initiative has ended and has since been merged with OpenAIRE) [1]. The DRIVER (Digital Repository Infrastructure for European Research) Project [5], was initiated in 2008 by the Association of European Universities and funded by the European Commission. The aim of the project was to create institutional repositories at universities in Europe, in their capacity as part of the network for free scientific information in all fields of science. As of 2015, DRIVER/OpenAIRE provides access to information from 9,433,258 scientific publications (papers, dissertations, books, lectures, research papers etc.), stored in over 5,776 datasets derived from 580 repositories from 38 countries from Europe and other continents. One of these 38 countries is Bulgaria which participates in DRIVER with 5 OA repositories: the digital archive of The Institute for Mathematics and Informatics - Bulgarian Academy of Sciences, Pensoft, New Bulgarian University, Medical University - Sofia and the Burgas Free University. While important, DRIVER is by no means the only major OA initiative in Europe. Digital Agenda: more open access to scientific information represents another one of these core projects [2]. The aim of this project is to act as a "public consultation" in regards to the access and storage of digital information. Digital Agenda began as the idea of the European Commission, Neelie Kroes (the vice-president for the Digital Agenda) and Máire Geoghegan-Quinn (Commissioner for Science and Innovation). According to the plan, researchers in Europe, engineers and entrepreneurs should be given quick and easy access to information relevant to their needs, in order to be on a par with their partners and colleagues throughout the rest of the world. An up-to-date digital infrastructure could play a key part in facilitating access to knowledge and promote the idea for the formation of a European scientific area. Nevertheless many challenges still remain, such as the high prices of academic publications, the growing volume of scientific data, and the need of selection, evaluation and storage of researcher's results. Open Access, defined as free access to academic work via the Web could help in this respect as a potential solution to some or all of the above issues. Access to information and the re-use of knowledge is the key goal of Digital Agenda for Europe and the Innovation Union [2]. Neelie Kroes stated the following in connection of the EU initiatives: "The results of publicly funded research should be circulated as widely as possible as a matter of principle. The broad dissemination of knowledge, within the European Research Area and beyond, is a key driver of progress in research and innovation, and thus for jobs and growth in Europe. Our vision is Open Access to scientific information so that all of us benefit as much as possible from investments in science. To accelerate scientific progress, but also for education, for innovation and for other creative re-use. For the same reason we must preserve scientific records for future generations" [6]. As can be seen from the above presented information, OA represents a core objective in the current and future information policies of the EU [17]. This statement is further supported by the European strategy for smart, sustainable and inclusive growth (Europe 2020) which states that the European Commission shall support OA results of publicly financed research. It shall also have as a goal to make OA a basic principle to publications for projects financed through EU research programs. 


\section{OA policies and initiatives: The Bulgarian experience}

Speaking of OA policies, what is the current state of OA in Bulgaria? It has to be noted that, in comparison with the above presented international experience, the current developments in regards to Open Access in Bulgaria are lagging somewhat behind, notable achievements notwithstanding. This is despite the fact that open access, as matter of interest, is the topic of several documents detailing the future developments of the Bulgarian scientific and educational sectors and that "due attention will be given to creation and development of scientific networks in which scientific information, knowledge and technology can be shared freely" [15]. Unfortunately, as of 2015, these documents remain purely theoretical and little has been done to have Open Access become an integral part of Bulgaria's scientific and academic societies $[2,3,21]$. In the few cases where OA has become a practical reality in Bulgaria, this mostly thanks to individual projects and initiatives driven by singular institutions rather than thanks to any support from the government. Speaking of such individual initiatives, the Bulgarian Academy of Sciences (BAS) intends to create a network of OA centers with the idea that its Institute of Mathematics and Informatics will be the coordinating body for this nationwide system. The institute aims to provide support to both academic organizations, as well as individual researchers. The aim here is to achieve integration between BAS, the public and industrial sectors, and to have ties between notable scientific centers, universities and other educations institution in the country be strengthened. The expectations regarding the success of this nationwide network are based around the future creation of Open Access repositories mainly in university libraries and scientific organizations. As of right now though, this network of academic repositories is fairly small as there are currently only 5 Bulgarian OA archives registered in OpenDOAR (Directory of Open Access Repositories) as can be seen in Table 4.

Another useful source of information regarding OA repositories in Bulgaria can be found in the OpenAIRE "European Open Access Repositories Landscape" infrastructure [4]. The following figure shown in Table 5 presents Bulgaria's standing in regards to the total number of Open Access documents published in comparison with several other European countries.

Table 4

Open Access repositories in Bulgaria registered in OpenDOAR (information relevant as of 30.06.2015) [9]

\begin{tabular}{|c|c|c|c|c|c|}
\hline Organization & Purpose & Profile & $\begin{array}{l}\text { Type of archived } \\
\text { documents }\end{array}$ & $\begin{array}{l}\text { Language(s) } \\
\text { of the } \\
\text { documents }\end{array}$ & $\begin{array}{l}\text { Number of } \\
\text { archived } \\
\text { documents }\end{array}$ \\
\hline Burgas Free University & $\begin{array}{l}\text { Research } \\
\text { documents of } \\
\text { the BFU }\end{array}$ & Inter-disciplinary & $\begin{array}{l}\text { Articles, } \\
\text { conference papers, } \\
\text { books }\end{array}$ & $\begin{array}{l}\text { Bulgarian, } \\
\text { English }\end{array}$ & 475 \\
\hline $\begin{array}{l}\text { Institute of Mathematics and } \\
\text { Informatics - BAS }\end{array}$ & $\begin{array}{l}\text { Research } \\
\text { documents of } \\
\text { the IMI }\end{array}$ & Inter-disciplinary & $\begin{array}{l}\text { Articles, } \\
\text { conference papers, } \\
\text { books }\end{array}$ & $\begin{array}{l}\text { Bulgarian, } \\
\text { English }\end{array}$ & 2,273 \\
\hline Pensoft Publishers & $\begin{array}{l}\text { Repository } \\
\text { for } \\
\text { documents }\end{array}$ & Inter-disciplinary & Books & English & 252 \\
\hline $\begin{array}{l}\text { Medical University of Sofia - } \\
\text { Central Medical Library }\end{array}$ & $\begin{array}{l}\text { Research } \\
\text { documents of } \\
\text { the MU }\end{array}$ & $\begin{array}{l}\text { Healthcare and } \\
\text { medicine }\end{array}$ & $\begin{array}{l}\text { Articles, } \\
\text { dissertations, } \\
\text { books, study } \\
\text { materials }\end{array}$ & $\begin{array}{l}\text { Bulgarian, } \\
\text { English }\end{array}$ & 603 \\
\hline New Bulgarian University & $\begin{array}{l}\text { Research } \\
\text { documents of } \\
\text { the NBU }\end{array}$ & Inter-disciplinary & $\begin{array}{l}\text { Articles, } \\
\text { dissertations, } \\
\text { books, study } \\
\text { materials }\end{array}$ & $\begin{array}{l}\text { Bulgarian, } \\
\text { English }\end{array}$ & 1,737 \\
\hline
\end{tabular}


Table 5

OpenAIRE data regarding number of OA repositories/documents per country (information relevant as of 30.06.2015) [10]

\begin{tabular}{lcc}
\hline Country & Number of repositories & Number of OA publications \\
\hline United Kingdom & 71 & $3,050,186$ \\
Germany & 78 & 561,665 \\
France & 16 & 477,334 \\
Bulgaria & $\mathbf{1 2}$ & $\mathbf{5 , 5 4 0}$ \\
Poland & 9 & 27,012 \\
Turkey & 11 & 2,161 \\
Hungary & 5 & 4,076 \\
\hline
\end{tabular}

As can be seen in the above provided information, Bulgaria lags considerably behind some of its EU co-members in regards to pure volume of OA information available online. This information source also shows that a greater number of $\mathrm{OA}$ repositories do not always correlate with a greater number of OA documents. A possible explanation for this can be found in the differences in document publication output rates in the various countries. Bulgaria, for example, has a fairly low publication output which could understandably also affect the number of OA documents published.

\section{OA policies: The bigger picture}

A key element for a wide spread acceptance of open access, as already hinted at previously, is the creation of institution, government and international level OA policies (this is particularly relevant for "green" OA solutions). Legal and organizational procedures for OA need to be introduced through these levels in order to turn them into a norm for the publication activities of scientists, as well as for the creation of institutional repositories. The emphasis is on the passing on in repositories of scientific results and publications, funded through public funds. Many organizations guarantee, that through adopted rules that namely they, and not commercial publishers shall have control over the copyright of scientists. According to data from Steven Harnad, Irina Lynden and Frederic Lynden 84 key policies $[10,15]$ have been adopted or are in the process of discussion at various parts in the world. Among these are those discussed by the European Research Council, the US National Institutes of Health - NIH, Research Councils UK (RCUK), Deutsche Forschungsgemeinschaft, European University Association, Digital Repository Federation in Japan, Harvard and Stanford Universities, Massachusetts Institute of Technology - USA and elsewhere. Part of the norms and positions reflected in the policies of the cited organizations are those connected with intentions for the structuring of global OA repositories with networks consisting of hundreds of participants. In regards to this, the policies specific the USA for normative regulation and quicker introduction of OA might be interesting to note [15]. After 2000, the efforts in this region of the world are focused towards working out a legal framework, which is aimed at obliging the National Institute of Health - NIH to provide access to its studies through open access. The specifics of this policy are to have research materials developed by the NIH and its staff be deposited in an OA repositories. Given the scientific production rate of the Institute, such a repository would provide access to a significant wealth of knowledge in health related scientific fields (the NIH annually spends over 29 billion dollars for the funding of projects, the results amounting to about 80,000 research papers and reports) [24]. In 2004, the United States Congress voted a document requiring scientists "to present in an electronic form completed research projects accompanied by an expert evaluation of the NIH within 12 
months of the date of publication" [24]. In this way, OA has received an official legal status concerning research work, funded through government funds in the USA. It is interesting to note the stated position of academia in regards to this. To quote Lee van Orsdel and Kathleen Born "The OA tsunami crested on February 12. In a move few anticipated, Harvard's Faculty of Arts and Sciences voted unanimously to give the university permission to post their scholarly articles in an institutional repository" [24]. The policy provides faculties with the right to self-archive peer-reviewed manuscripts written by faculty staff when signing publisher agreements (though individual faculties can get a waiver by asking for it in writing). About two-thirds of publishers already grant such permission. The one-third that don't currently allow self-archiving will find themselves in a tough spot - conform to the current policy or lose access to the works of Harvard authors which would hurt said publishers reputation (and more importantly, revenue). Harvard presents the first example of an OA university policy in the United States (and the world, in general) to be initiated by individual faculties rather than administrators. Therein lays its importance. Through its OA policy, Harvard faculties voted for more control over their intellectual output and for the right to use and share it widely with the rest of the world.

The adoption of such measures in favor of OA is by no means a straightforward or unanimously welcome tendency. Publishers and other traditional distributors of scientific information are aware of the potential threat to their future that is OA. Their responses are expressed through various actions lobbying, financial pressure, political pressure, statements of the threat that OA poses on the security of information resources etc. Most (though not all) publishers do not approve of open access, not as much as a technology per se, but rather as a business model. The transition from the traditional business model towards OA means they have to give up the income from subscriptions and seek stable flows of income from authors, subsidies or advertising. Active resistance against the legislative initiatives for open access to research, funded by public funding, is a priority for many large academic and research focused publishers. Their efforts are directed not only towards researchers and professional associations, defending copyright, but also towards political institutions in the USA and Europe [24].

\section{The development of $\mathrm{OA}$ in recent years}

In spite of the presented clear resistance towards OA, the OutSell report, with a focus on the information industry, provides data that shows that in the last few years $9.6 \%$ of the titles in peer-reviewed periodicals operate in an OA regime. (April 2009). Michael Laakso and other colleagues of his claim that $7.7 \%$ of research papers in 2009 were presented in OA [11]. According to data from the Directory of Open Access Repositories-Open (DOAR) the initiative has been picking up speed [18,19]. As can be seen in Table 6, as of October of 2015, 2,988 electronic OA depositories have been functioning throughout the world.

Table 6

Registered repositories - according to continents (information relevant as of 25.10.2015) [10,18,19]

\begin{tabular}{lcr}
\hline Repositories per continent & Percentage of registered (\%) & Number of registered \\
\hline Europe & 44.2 & 1,321 \\
North America & 19.1 & 571 \\
Asia & 20.0 & 598 \\
Others & 16.7 & 498 \\
Total & $\mathbf{1 0 0}$ & $\mathbf{2 , 9 8 8}$ \\
\hline
\end{tabular}


Table 7

Number of repositories over the years - 2006-2015 (towards 25.10.2015) [18,19,21]

\begin{tabular}{lccccccccc}
\hline Year & 2006 & 2007 & 2008 & 2009 & 2010 & 2011 & 2012 & 2013 & 2015 \\
\hline Number of repositories & 400 & 600 & 800 & 1,200 & 1,600 & 2,000 & 2,167 & 2,476 & 2,998 \\
\hline
\end{tabular}

Table 8

Number of repositories depending the type of archived documents (towards 25.10.2015) [2,5,13]

\begin{tabular}{lc}
\hline Type of documents provided & Number of repositories depending on the type documents \\
\hline Papers from journals & 2,085 \\
Books & 1,124 \\
Papers from conferences & 1,082 \\
Unpublished material & 1,087 \\
Dissertations & 1,635 \\
Teaching material & 493 \\
Multimedia & 694 \\
Patents & 91 \\
References & 427 \\
Software & 51 \\
Special material & 504 \\
Theses and papers & 1,635 \\
\hline
\end{tabular}

The dynamics of the increase of the number of repositories over the last years is what we are interested in. Table 7 shows that their number has been growing on average by about $30 \%$ annually.

Repositories functioning according to countries (2015): USA - $18.8 \%$ of the repositories; Great Britain - 9.6\%; Germany - 7\%; Japan - 6\% etc. 46 electronic depositories have been created in Sweden; 87 - in Spain; 152 in Germany; 408 in the USA; 14 in Russia; 75 in Poland; 208 in Great Britain; 66 in France; 24 in the Netherlands; 44 in Norway etc. A network of electronic depositories is actively being built up in Japan in line with DRIVER - a total of 136. A similar approach is currently underway in China - 33 repositories, 53 in India, 62 in Brazil, 57 in Australia; 12 in the Republic of Korea.

For countries comparable in certain indices with Bulgaria, which has 6 repositories, the data are as follows: Belgium 29, Greece 14, Denmark 10, Austria 9, Croatia 5, Serbia 1, Slovenia 4, the Czech Republic 6, Portugal 41, Finland 15, Romania 1, Hungary 12, Lithuania 3, Latvia 3 etc.

$87 \%$ of the repositories are institutional in nature and associated with universities, libraries and research institutes, $13 \%$ are attached to state, business of other organizations. Concerning the type of documents stored and offered the number for repositories is presented in Table 8.

The spread of information in regards to the languages used within materials is as follows (2015): 1,587 in English, 223 in Spanish, 183 in German, 126 in French, 137 in Japanese, 109 in Portuguese, 96 in Chinese, 67 in Italian, 44 in Norwegian, 15 in Greek.

In spite of the difficulties, the barriers and resistance, what has been achieved so far inspires confidence in OA $[9,21]$. The first steps have been made. The desire towards the creation a more effective and cheaper global network for communication in science is evident. Such a network should possess enormous databases of information. The system should outline the road of coordination of relationships between the various scientific fields. Alongside with this it should resolve another basic issue: it should make it possible for teams of researchers, regardless where they are, to work together in an interactive mode throughout the entire research cycle - from the exchange of ideas, methods, instrumentarium, data and information to the completion of the final result (research paper, report etc.). An example of this can 
be illustrated with the collaborative Wikipedia electronic encyclopedia, which in spite of its shortcomings, "has adopted a model, since its foundation in 2001, where more than 82,000 authors from different places in the world have taken part in its compiling. The outcome is the publication of 17 million articles in 270 languages. About 400 million readers monthly visit the encyclopedia. Encyclopedias are a special type of scientific product. In spite of that it is indicative how an important achievement may be created and developed, making use of openness and the inclusion of critical groups of participants" [12,13,25]. This idea of this type collaborative research has become popular with the term "social production" [12]. This is something which shall change the world of science and the philosophy of science as well. The changes shall affect and shake not only scientists and specialists in the fields of library and information sciences. This change could very well have an effect on all of the players in the arena of science, as well as all other participants in its communication chain - authors, publishers, distributors of information and literature, bookshops, creators of databases, as well as management bodies and commissions dealing with knowledge and information. With that said, we have to point out that scientific communication is yet to truly transform into an OA based utopia. Traditional channels of information distribution still have their part to play and are by no means "a thing of the past". It is important to strike a balance between the old and new.

\section{Open access and Bulgaria: Where are we now?}

As already stated in a previous part of this text, Bulgaria's current OA initiatives and policies are currently facing some challenges in regards to the widespread adoption of this new (for the country) publishing model. This current tendency can be directly tied to several major factors. Some of the more notable of these include to following [2,3]:

- The low level of financing of science and research in Bulgaria (roughly $0.5 \%$ of the country's GDP, whereas the recommended norm in the rest of the EU is 3\%).

- There exists a declared desire to have Open Access become part of the Bulgarian scientific society. Yet this desire is not backed by practical suggestions as to how an OA framework can be created in the country.

- The idea of Open Access is still largely unknown to Bulgarian scientists. There is also their lack of determination to convert to a more digitally focused method of publishing their research results (as opposed to the more traditional printed publication platforms).

- The lack of a common vision for the creation of OA repositories. As stated above, current Open Access initiatives in Bulgaria are handled by individual institutions and there is distinct lack of cooperation in regards to the creation of unified OA network.

- An existing crisis in the Bulgarian publishing sector in regards to scientific periodicals and literature that is mostly the result of poor financing.

- The current trend of having Bulgarian scientists focus on having their works be published in renowned foreign peer-reviewed journals and databases with high impact factors as opposed to local publications.

- The lack of qualified specialists who can work towards the implementation of OA in Bulgaria.

- Lack of financing for the development of the Open Access sector in Bulgaria. Despite the OA model being focused on providing free access to scientific information to all who would benefit from it, the actual implementation of a functioning framework nevertheless required adequate financial resources. 
Apart from the above mentioned there are two additional factors that have a significant impact on the current development of the scientific fields in Bulgaria. These factors also have their effect on the Open Access and will therefore be mentioned in this report. The first of these is the notable lack of a proper apparatus for scientific critique and review in Bulgarian universities and scientific organizations. The reviewing institution, as of now, has a mostly formal role in Bulgarian academic publishing. In turn, this has led to a decrease of both the quality, as well as the prestige of Bulgarian scientific publications. The second factor is connected with the above mentioned and has to do with the decrease in the quality of the requirements and criteria for the professional development of academic staff in Bulgarian scientific and educational institutions. This has led to several tendencies that have negative impact on the Bulgarian academic society as a whole. These include:

- The lack of encouragement for the creation of higher quality scientific literature.

- The decreased number of documents published per individual researchers.

- The isolation of part of the Bulgarian scientific society from the greater worldwide scientific community and achievements.

The Bulgarian scientific community is a relatively small one in terms of resources and lacks the capabilities to produce a significant quantity of research documents. Even so, despite its shortcomings, the Bulgarian research community has managed to gain some level of international recognition for its scientific achievements and publications. There are notable Bulgarian scientific publications in all 21 major scientific areas cover in the Essential Scientific Indicators. Similarly, in SCOPUS, Bulgarian scientists have managed to publish important research papers in all 26 core categories [2,3]. Based on information gained from the above two sources, there are a several scientific sectors in which the Bulgarian scientific community has managed to achieve some level of international renown. Notable among these are publications in the fields of agriculture, chemistry, physics and medicine (and the various sub-fields connected with them). On the other hand though, some scientific sectors such as the social and humanitarian sciences are poorly represented in Bulgarian scientific literature. This could hopefully be mitigated with gradual introduction of Open Access publishing.

In the past several years, another major issue emerged that has had a significant impact on the ability of Bulgaria to participate in the sharing of scientific information with the international research community. This problem is connected with the lack of resources in Bulgaria's major scientific libraries. This prevents these institutions from sharing information with other scientific and university libraries, as well as other academic organizations from other countries. Thus, since many Bulgarian scientists rely on these libraries for research information, the Bulgarian academic community has some difficulty in gaining access to part of the current scientific output of their colleagues throughout the world. The information presented in the current reports of the National Library "St. Cyril and Methodius", University Library "St. Kliment Ohridski" and the Central Library of the Bulgarian Academy of Sciences contains some highly troubling statements in regards to the ability of these institutions to maintain effective international book exchange programs. These libraries lack the required financial resources to buy publications that they can include in these exchange programs. What is more, these institutions lack the financial resources required for them to be able to send these publications to their exchange partners (provided, as mentioned above, that they can buy them in the first place) $[13,16]$. As mentioned above, these issues effectively isolate the Bulgarian academic community from the rest of the scientific world. The creation of electronic information systems such as OA repositories and journals could mitigate some of these issues but the current efforts in regards to this, as mentioned above, have so far been made on an individual basis with a general overlaying framework. This leads to lack of coordination in regards to the creation 
and support of these information systems. Furthermore, not only are the financial resources provided to the Bulgarian scientific and academic institutions scarce but what is provided is fairly poorly managed (lack of an effective spending strategy). All of this means that the Bulgarian scientific community should be looking to create and/or participate in national and inter-institutional initiatives and projects that help create a unified framework for the effective allocation and use of resources.

\section{Conclusion}

In the years to come, the international academic society shall have to decide to resolve the matters of scientific communication in such a way that will enable society to better preserve its intellectual heritage as well as move towards making new discoveries that change our view of the world. Open access is one tool that could be used to help achieve the above stated goal. As time passes, researchers shall increasingly have to learn how to manage the information flow (both theirs as well as that of their colleagues) themselves as to be able to achieve their individual (or collective) scientific goals. Towards the end of this paper, we would like to take the liberty of resorting to Steven Harnad's words in his address to students in his publication "The Awakening of the Sleeping Giant. University mandates for Open Access": "The world's universities are OA's sleeping giant. They have everything to gain from mandating OA, but they are being extremely slow to realize it and to do something about it. Unlike you students, they have not grown up in the online age, and to them the online medium's potential is not yet as transparent and natural as it is to you. You can help awaken your university's sense of its own need for OA, as well as its awareness of the benefits of OA, and the means of attaining them, by making yourselves heard" [10]. The benefits of open access for scientific information are many but its proper application cannot happen on its own. For OA to truly become a new paradigm in the scientific publishing sector, researchers from the international community (Bulgaria included) must work towards the creation of effective policies and technological frameworks that will make the sharing and re-use of scientific information an easier endeavour. For Bulgaria in particular, with its current issues in both the scientific and publishing sectors, OA could very well turn out to be a major opportunity that could enable the nation's scientific community to improve its dialogue with the greater international scientific community, as well as improve the overall quality of its research output.

\section{Notes}

The first journals appeared in the 17th century. Amongst them were the "Journal des Sçavans" and "Philosophical Transactions of the Royal Society", which began coming out in 1665. According to UNESCO data at present about 200,000 serials in the field of science come out. Data from prof. Borislav Toshev shows that about 75,000 of these are subject to peer-review from all fields, indexing, evaluation in secondary sources - printed and electronic, for instance S Chemical Abstracts, Sociological Abstracts, America: History \& Life, .... Web of Science (Thomson Reuters), SCOPUS (Elsevier) [9]. They are selected after applying a strict evaluation based on certain indices. Journals which are not in this system are generally marked as marginal and publishing scientific results in them is not recommended. Two elite groups exist in the world for peer-reviewing, indexing and evaluation - about 7,500 journals are controlled by Thomson Reuters (formerly Thomson Scientific and even earlier ISI which belonged to Garfield in Philadelphia). SCOPUS of Elsevier the European parallel of Thomson Reuters. At present SCOPUS controls about 15,000 peer-reviewed journals (some of them Proceedings of Conferences), 
which were selected there after a strict evaluation of certain indices. Both formations give their journals an annual scientific value, the most popular of which is the (impact factor (IF), an intensive factor which is a characteristic for the journal, not a reference for the authors who publish in it). With equal value is a similar indicator, calculated through a different procedure, known as Journal Citation Reports (JCR). Both JCR and IF are considered to be the current paradigms in the field of evaluating the value of academic information sources.

\section{References}

[1] Arj.no, Petition for guaranteed public access to publicly-funded research results I ARJ [Internet], 2007, available at: http:// www.arj.no/2007/01/24/petition-for-guaranteed-public-access-to-publicly-funded-research-results/ [cited 3 November 2015].

[2] C. Bailey, What Is Open Access? Key Strategic, Technical and Economic Aspects, Chandos Publishing, Oxford, 2006.

[3] Biomedcentral.com, BioMed CentrallAbout us, available at: http://www.biomedcentral.com/about [cited 3 November 2015].

[4] Doaj.org, Directory of open access journals [Internet], available at: http://www.doaj.org [cited 3 November 2015].

[5] Driver-support.eu, DRIVER - Digital Repository Infrastructure Vision for European Research, 2015, available at: http:// www.driver-support.eu/ [cited 3 November 2015].

[6] Europa.eu, European Commission - PRESS RELEASES - Press release - Digital Agenda: more open access to scientific information - Commission seeks views [Internet], 2015, available at: http://europa.eu/rapid/pressReleasesAction.do? reference=IP/11/890 [cited 3 November 2015].

[7] S. Harnad, Self-archiving initiative, Nature 410 (2001), 1024-1025, available at: http://www.cogprints.og/1640 [cited 3 November 2015].

[8] S. Harnad and T. Brody, Comparing the impact of open access (OA) vs. non-OA articles in the same journals, D-Lib Magazine 10 (2004), 17-22, available at: http://www.eprints.ecs.soton.ac.uk [cited 3 November 2015].

[9] Я. Хагерлид, Программа "Open Access.se" - шведский опыт координации поддержки программ Открытого доступа, Науч. и техн. библ. 8 (2009), 24-32.

[10] С. Харнад, Пробуждение "спящего гиганта". Университецкие мандаты на Открытый доступ, Науч. и техн. библ. 10 (2009), 62-72.

[11] M. Laakso, P. Welling, H. Bukvova, L. Nyman, B. Björk and T. Hedlund, The development of open access journal publishing from 1993 to 2009, PLoS ONE 6(6) (2011), e20961.

[12] D. Lewis, From stacks to the web: The transformation of Academic Library Collecting (Preprint) I LJ INFOdocket, Infodocket.com, 2015, available at: http://infodocket.com/2012/01/12/from-stacks-to-the-web-the-transformation-ofacademic-library-collecting-preprint [cited 3 November 2015].

[13] D. Lewis, The inevitability of open access, College \& Research Libraries 2015;:crl-299, available at: http://crl.acrl.org/ content/early/2011/09/21/crl-299.full.pdf+html [cited 3 November 2015].

[14] Lib-sh.lsuhsc.edu, Open access to the scientific literature. A summary of the issues, 2015, available at: http://lib-sh.lsuhsc. edu/openaccess.html [cited 3 November 2015].

[15] И. Линден and Ф. Линден, Открытый доступ: “зеленый путь" и "золотой путь", Науч. и техн. библ. 7 (2009), 30-43.

[16] H. Morrison and J. Szczepansk, Collecting for the world. OA Librarian, Open access resources by and for librarians, Oalibrarian.blogspot.com, 2005, available at: http://oalibrarian.blogspot.com/2005/12/jan-szczepanskicollecting-for-world.html [cited 3 November 2015].

[17] Openaire.eu, OpenAIRE, Open Access Infrastructure Research for Europe [Internet], 2015, available at: http://www. openaire.eu [cited 3 November 2015].

[18] Opendoar.org, OpenDOAR - Directory of Open Access Repositories [cited 3 November].

[19] Opendoar.org, OpenDOAR Chart, available at: http://www.opendoar.org/onechart.php [cited 3 November 2015].

[20] Plos.org, Journals - PLOS, Public Library of Science, Available from: http://www.plos.org/publications/journals [cited 3 November 2015].

[21] Я. Шрайберг, Состояние открытого доступа на бибиточно-информационном пространстве Росии и СНГ, Науч и техн библ. 11 (2009), 29-38.

[22] Sherpa.ac.uk, SHERPA [Securing a Hybrid Environment for Research Preservation and Access] [Internet], 2015, available at: http://www.sherpa.ac.uk [cited 3 November 2015].

[23] A. Swan, Overview of Scholarly Communication. Key Strategic, Technical and Economic Aspects, Chandos Publishing, Oxford, 2006. 
[24] L. Van Orsdel and K. Born, Periodicals price survey 2008. Embracing openness. Global initiatives and startling successes hint at the profound implications of open access on journal publishing, Library Journal 4 (2008), 10-15.

[25] Wikipedia, About [Internet], 2015, available at: http://en.wikipedia.org/wiki/Wikipedia:About [cited 3 November 2015]. 